\title{
Diphtheria presenting in the accident and emergency department
}

\author{
R. F. WALTERS
}

Department of Accident and Emergency Medicine, Middlesex Hospital, London, England

\section{SUMMARY}

A case of diphtheria encountered in the accident and emergency department is described. In addition, 38 cases of diphtheria have been analysed, and demonstrate that, although now rare in this country, the disease still exists and its clinical features remain unchanged. It presents almost as often in the accident and emergency department as it does to the general practitioner and remains overwhelmingly a disease of children. Diphtheria is still a notifiable disease. The diagnosis must be made clinically and appropriate action taken before the bacteriological confirmation is received. This prevents unnecessary delay in treatment and makes contact tracing less arduous.

\section{INTRODUCTION}

During the 15 years from 1970-1984, 80 cases of diphtheria were notified in England and Wales of which seven $(8.75 \%)$ proved fatal. During a similar 15 -year period from 1920-1934, there were no less than 829152 notifications of diphtheria and 49995 (6\%) attributed deaths (Fig. 1). The widespread introduction of diphtheria vaccine in the mid 1930s has transformed a once common disease into one so rare that few current doctors have seen a case outside the pages of a textbook. However, it does still exist and a case of diphtheria which presented in an accident and emergency (A\&E) department as a simple sore throat is described. An analysis has also been made of 38 other recorded cases which occurred between 1970 and 1984, and for which clinical information is available.

Correspondence: Dr R. F. Walters, Southampton Eye Hospital, Wilton Avenue, Southampton S09 4XW, England 


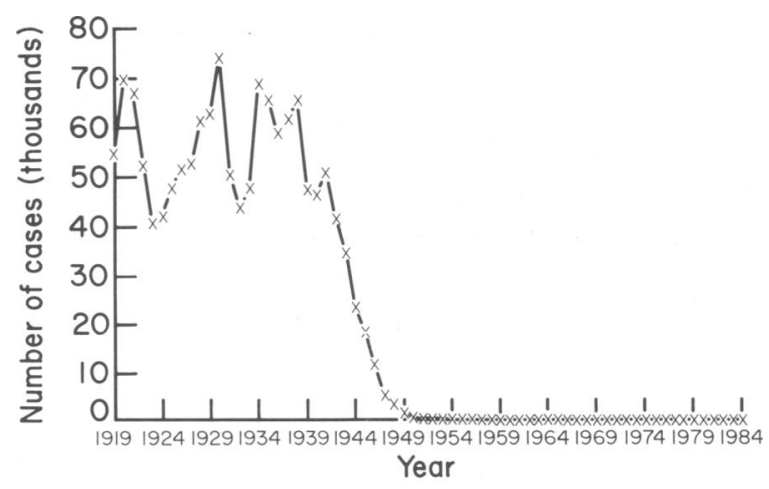

Fig. 1 Annual corrected notifications of diphtheria.

\section{CASE REPORT}

A 52-year-old man of Asian origin presented to an A\&E department one Sunday morning with the common complaint of a sore throat which had been present for the past week. He had been to his general practitioner 4 days previously and had beenc prescribed oral Tetracycline $250 \mathrm{mg}$ qds since he was known to be allergic to Penicillim.. His throat symptoms had not improved with this treatment, and he had developed intermittent headache, watering eyes and fever. There was no known recent contagt s with similar illness and he had not been abroad during the past year. He suffered from polycythaemia rubra vera and he had a history of mild renal impairment. Onळे examination, he was apyrexial and appeared systemically well. Examination of the $\overrightarrow{\vec{\overrightarrow{ }}}$ throat revealed an inflamed oropharynx with a small area of whitish membranous $\Xi$ exudate. He had bilateral enlarged cervical lymph nodes but no other clinical signs. The? infected oropharynx with fixed membrane raised a clinical suspicion of diphtheria and a: throat swab was sent to the microbiology laboratory with a specific request for inclusion $\frac{\Phi}{3}$ of Corynebacterium culture in addition to normal throat pathogens. The patient was:prescribed oral Erythromycin Stearate $500 \mathrm{mg}$ bd and since he was not systemically $\underset{\text {. }}{\text {. }}$. unwell he was allowed home. Four days later the throat swab was reported as growingo Corynebacterium diphtheria varmitis. The Elek test for toxigenicity was later found to be positive.

The laboratory telephoned the A\&E department on a Thursday morning and steps were immediately taken to contact the patient. This proved difficult because he was no longer living at the address he had given and because his work telephone number, ${ }^{\circ}$ recorded at his new lodgings, was found to be inaccurate. He was eventually contacted later the same afternoon and arrangements were made for him to be admitted directlyw from his place of work to Coppetts Wood Hospital for Infectious Diseases. He wase initially reluctant to enter hospital as he was feeling well and had no residual symptoms He was placed in isolation and continued on Erythromycin, but Antitoxin was not givene? although the Schick test was later found to be positive, denoting his susceptibility to the 
toxin. No complications developed but the patient remained in hospital for 6 weeks, being discharged only after a series of six throat and nose swabs proved negative.

As soon as the laboratory diagnosis was known, the local medical officer of Environmental Health was informed and he notified his colleagues in the other three areas in which the patient was known to have recent direct contacts. The four areas involved consisted of two in which the patient had been living (and in one of which he also worked), the area of residence of his wife and family, from whom he was separated but with whom he still had contact, and the area of the hospital to which he first presented. Contact tracing was thus an arduous and labour intensive process, and a total of 52 close contacts were identified. Eight of these contacts were hospital staff working in the A\&E department, 25 were patients who had attended the A \& E department on the same morning, three were members of his family, four resided at his lodgings, eight shared his place of work and four were close acquaintances. All of them were eventually traced and were started on a 4-day course of Erythromycin Stearate after throat swabs had been taken. No source for the infection was found and no contacts appeared to have contracted the disease.

\section{ANALYSIS OF 38 CASES OF DIPHTHERIA, 1970-1984}

Detailed analysis was possible in 38 out of the 80 cases of diphtheria reported between the years of 1970 and 1984. The information was gathered from the communicable disease reports issued by the Public Health Laboratory Service at Colindale in North London. This information is tabulated in Table 1 and shows that diphtheria remains overwhelmingly a disease of children since 21 of the 29 patients in whom the age was specified were aged 15 or less. In addition, of the nine not given a precise age, six were described as being aged between 8 and 11 years, and two others were described as a 'schoolgirl' and a 'child' respectively. Thus $78 \%$ were probably aged 15 or less. The patient described in this paper is the only one known to be over 40 years of age. The most common presenting complaint was a sore throat and, in those instances for which information is available, almost as many of the patients presented at hospital (especially in the A\&E department) as were seen first by their general practitioner. It is recognised that immunization against diphtheria does not confer complete protection, and it is of interest that at least six of the patients were stated to have been fully immunized and a further two had been part-immunized.

\section{DISCUSSION}

Although the incidence of diphtheria has dramatically declined during the last 50 years, the clinical features remain unchanged. The combination of a sore throat with a classical white membranous exudate on the tonsils and/or the pharynx should enable an easy provisional diagnosis and ensure early bacteriological confirmation. However, very few doctors currently working in the UK have encountered diphtheria in their clinical 





practice, and very few microbiology laboratories routinely screen nose and throat swabs for Corynebacterium diphtheriae. Equally, few hospital pharmacies now stock the antitoxin which was once given routinely as soon as the clinical diagnosis was suspected. These factors serve to emphasise the extreme rarity of a once common disease which may still present with benign simplicity to the unsuspecting clinician. However, diphtheria remains prevalent in many Third World countries and it should always be included in the differential diagnosis when the casualty officer is asked to see a patient with 'just another sore throat'. Perhaps the most important lesson to be learnt from the case described is the necessity for a Casualty Officer to trust his clinical acumen and to take immediate appropriate action without awaiting confirmatory laboratory diagnosis. Much clinical administrative time could have been saved if the patient had been admitted to an appropriate unit when he first presented but one cannot help wondering whether there may be other occasions on which diphtheria passes without recognition.

\section{ACKNOWLEDGEMENTS}

I am indebted to Dr D. J. Williams, Consultant to the Accident and Emergency Department at St Thomas' Hospital, London SE1 (formerly Accident and Emergency Consultant at the Middlesex Hospital, London W1), for his help and advice in preparing this report.

Especial thanks too are due to Dr Norman Noah and other staff of the Public Health Laboratory Service, Colindale, London NW9, for their help in providing the background data from which the analysis in the report was largely obtained.

\section{REFERENCES}

Anderson J. R. (ed.) (1978) Muir's Textbook of Pathology. London, Edward Arnold.

Morrison A. G., Roberts \& Llywelyn (1957) fournal of Hygiene 37, 388-92.

Ramsay A. M. \& Emond R. T. D. (1978) Infectious Diseases. London, Heineman Medical Books Ltd.

Taylor I., Tomlinson A. J. H. \& Davies J. R. (1962) Diphtheria control in the 1960s. Royal Society of Health fournal 82, 158-64. 